\title{
The Antigenic Structure of PPLO (Mycoplasma hominis) and Related Bacteria
}

\author{
By PHYLLIS PEASE \\ Department of Virology and Bacteriology, University of Birmingham
}

(Received 28 December 1964)

\begin{abstract}
SUMMARY
By gel-diffusion precipitin and antigen-absorption tests, 34 strains of PPLO (Mycoplasma hominis, types 1-4) were examined, and 15 antigenic components recognized. Antigens $a, b, f$ and $g$ were common to types 1, 2 and 4 ; $c$ was specific to type $1 ; h$ was specific to type 2 . Type 3 was antigenically unrelated to the remainder. Its two recognizable components were named $j$ and $k$. Three further antigens in type 1 were recognized as 17 , 39 and 40, previously defined in strains of Haemophilus and Corynebacterium associated with mycoplasma-like variants (Pease \& Laughton, 1965); antigen 40 also occurred in type 2 . Two diffusible antigens, $\alpha$ and $\beta$, were detected in strains of types 1 and 4 ; these and also $g$ were found to be shared with the bacterial strains.

All genital strains of mycoplasma isolated in this laboratory belonged to type 1 , all oral strains to type 4 ; one rat strain belonged to type 2 .

Distribution of antigenic components in strains of mycoplasma and in different strains of bacteria, including those believed to be derived from mycoplasma (or vice versa), and also in others, notably Haemophilus influenzae, supports previous claims of relationship between Mycoplasma hominis types 1, 2 and 4, Corynebacterium and Haemophilus. The validity of Mycoplasma as a distinct group of micro-organisms is thus called into question.
\end{abstract}

\section{INTRODUCTION}

Several attempts have been made to classify Mycoplasma hominis and similar PPLO by serological methods, including : complement fixation (Huijsmans-Evers \& Ruys, 1956; Card, 1959; Coriell, Fabrizio \& Wilson, 1959; Taylor-Robinson, Somerson, Turner \& Chanock, 1963); agglutination (Norman, Saslaw \& Kuhn, 1950; Nicol \& Edward, 1953; Edward \& Fitzgerald, 1954; Tourtelotte \& Jacobs, 1959); growth inhibition by antibody (Nicol \& Edward, 1953; Edward \& Fitzgerald, 1954; Huijsmans-Evers \& Ruys, 1956); and gel precipitation (Villemot \& Provost, 1959; Pease \& Laughton, 1962; Pease, 1962; Taylor-Robinson et al. 1963; Lemcke, 1964). There is general agreement that human mycoplasmas fall into four main groups, represented by $M$. hominis, types 1-4 (Huijsmans-Evers \& Ruys, 1956; Edward \& Freundt, 1956). Complement-fixation and gel-diffusion precipitins have provided evidence of relationship between these groups, especially between types 1 and 4; the degree of relationship, the place of types 2 and 3 and of other PPLO especially those of animal origin, has remained obscure. Specific names have also been applied to the various types by some authorities.

The purpose of the present work was to determine the relationship between those PPLO claimed to be L-forms of Corynebacterium and Haemophilus species (Pease \& 
Laughton, 1962; Pease, 1962; Pease \& Bisset, 1962), to determine the number and distribution of the antigens, and to investigate the possible antigenic relationships between PPLO and bacteria. The antigenic structure of some strains of bacteria believed to be derived from, or associated with, PPLO was described by Pease \& Laughton (1965).

\section{METHODS}

Mycoplasma strains used. Fifteen strains (Gt. 1 to Gt. 15 inclusive) were isolated from human genital tracts by the methods of Pease \& Laughton (1962). Eleven human oral strains (Or. 1 to Or. 11 inclusive) and one strain (E) from the respiratory passages of a rat were isolated directly upon serum agar by Mr B. C. Cole in this laboratory. Three strains of type 1 (н 26, D 419, H50 R), one of type 2 (Campo), one of type 3 (G), and one of type 4 (H 110) were provided by Dr D. G. ff. Edward (Wellcome Research Laboratories).

Bacterial strains used. Seven strains of Corynebacterium cervicis, ten of Haemophilus vaginalis, five of $H$. influenzae and one of $H$. parainfluenzae, listed by Pease \& Laughton (1965), were used. Two strains of Corynebacterium derived by Mr B. C. Cole from PPLO Or. 4 and Or. 9 (Bact. Or. 4 and Bact. Or. 9), one Corynebacterium (D5) derived from mycoplasma (Campo) by Dr H. E. Morton, a strain of C. cervicis (sM) described by Pease (1962), associated with a Streptobacillus moniliformis strain. One strain each of $\boldsymbol{H}$. aegyptius and $\boldsymbol{H}$. aphrophilus from the National Collection of Type Cultures.

Serology. For the preparation of antigens, 2 l. liquid medium (composition: Lab Lemco $1 \%$, w/v; Oxoid yeast extract $0.5 \%$, w/v; Proteose peptone $1.0 \%$, w/v; $\mathrm{NaCl} 0.5 \%, \mathrm{w} / \mathrm{v}$; horse serum $10 \%, \mathrm{v} / \mathrm{v}$, with arginine $0.2 \%, \mathrm{w} / \mathrm{v}$, for the oral strains; $\mathrm{pH} \mathrm{7 \cdot 8)}$ were inoculated with the centrifuged deposit from a $48 \mathrm{hr}$ culture in the same medium. The culture was incubated for 5 days at $37^{\circ}$ and the organisms centrifuged down and washed 3 times in physiological saline containing $0 \cdot 2 \%(\mathrm{v} / \mathrm{v})$ of $40 \%(\mathrm{w} / \mathrm{v})$ formaldehyde. The entire yield of organisms was again concentrated to $2 \mathrm{ml}$. in formol saline and subjected to ultrasonic disintegration for $5 \mathrm{~min}$. Standardization by opacity was impracticable. The disintegrated organisms were centrifuged and the deposit was made up to $6 \mathrm{ml}$. in formol saline.

Immunization and gel-diffusion precipitin tests were done by the techniques described by Pease \& Laughton (1965) and similar controls were used. It was also possible to grow the antigenically important derived bacteria, Bact. Or. 4 and Bact. Or. 9, on media without Fildes extract, thus providing an additional control against false reactions from this source. A technique of antigenic absorption was also used. It was found convenient to reverse the usual procedure and to absorb antigen with serum, instead of vice versa. One drop of serum added to a cup containing one drop of antigen was usually adequate to absorb all the antigens for which antibodies were present in the serum, as controlled by the same serum in a contiguous cup. For direct comparison with such absorbed antigens, the reactions were made at the same dilution ( $50 \%$ ). This technique permitted absorptions to be done successfully with the very small quantities of mycoplasma antigens that were available. 


\section{RESULTS}

Ten antisera were prepared against Mycoplasma hominis strains Gt. 2, Gt. 3; Or. 1, Or. 2, Or. 3, Or. 4 ; н 26, Campo, G, н 110. These antisera were tested against all 33 strains. The results are shown in Table 1, where the vertical lines represent the

Table 1. Gel-diffusion precipitin reactions, showing relationships between strains of Mycoplasma hominis

\begin{tabular}{|c|c|c|c|c|c|c|c|c|c|c|}
\hline & & & & & Antisera & & & & & \\
\hline & & Type 1 & & Type 2 & Type 3 & & & Type 4 & & \\
\hline Antigens & н 26 & Gt. 2 & Gt. 3 & Campo & a & H 110 & Or. 1 & Or. 2 & Or. 3 & Or. 4 \\
\hline н 26 & $H$ & $H$ & +1 & $\longrightarrow$ & & $\longrightarrow$ & $H$ & H & $\longrightarrow$ & + \\
\hline Gt. 1 & $H$ & $H$ & +1 & -1 & - & + & + & - & + & + \\
\hline Gt. 2 & - & $+1+$ & -1 & + & & & 1 & + & $千$ & 1 \\
\hline Gt. 3 & + & + & +1 & $\longrightarrow$ & - & $\longrightarrow$ & + & + & $\longrightarrow$ & $\longrightarrow$ \\
\hline Gt. 4 & -1 & + & + & $\longrightarrow$ & & $\longrightarrow$ & $\longrightarrow$ & $\longrightarrow$ & + & $十$ \\
\hline Gt. 5 & + & +1 & +1 & + & - & + & H & + & + & + \\
\hline Gt. 6 & +1 & + & $-1-$ & + & - & + & $H$ & H & $\longrightarrow$ & - \\
\hline Gt. 7 & +1 & +1 & +1 & + & & + & + & $H$ & + & + \\
\hline Gt. 8 & 1 & + & +1 & + & & + & + & & + & + \\
\hline Gt. 9 & +1 & + & + & + & & + & + & + & + & + \\
\hline Gt. 10 & $H$ & + & -1 & + & T & + & + & + & + & + \\
\hline Gt. 11 & 1 & + & +1 & + & - & -1 & + & + & + & -1 \\
\hline Gt. 12 & +1 & +1 & $H$ & + & 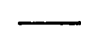 & 1 & $H$ & + & $十$ & + \\
\hline Gt. 13 & +1 & + & +1 & + & & $\longrightarrow$ & H & + & - & $\longrightarrow$ \\
\hline Gt. 14 & + & + & + & + & & + & + & + & + & + \\
\hline Gt. 15 & + & + & -1 & + & & & \# & $十$ & $\longrightarrow$ & - \\
\hline D 419 & +1 & $+1+$ & - & 1 & - & + & + & & + & + \\
\hline Campo & $\longrightarrow$ & & 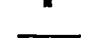 & +1 & $\longrightarrow$ & $\longrightarrow$ & + & 1 & $\bar{L}$ & L \\
\hline $\mathbf{E}$ & + & - & + & H+H & - & - & $H$ & $H$ & $\longrightarrow$ & - \\
\hline G & $\Gamma$ & & 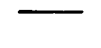 & 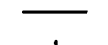 & H & - & - & - & & $\longrightarrow$ \\
\hline н 110 & + & & $\overline{ }$ & + & - & $+1+$ & $\mathrm{HH}$ & $\mathrm{HH}$ & $\longrightarrow$ & +1 \\
\hline Or. 1 & + & & + & +1 & & H+H & H+ & HH & $\overline{1}$ & $1+$ \\
\hline Or. 2 & + & & + & + & & H+1 & $H$ & $H$ & + & + \\
\hline Or. 3 & + & & & $\longrightarrow$ & & + & $\longrightarrow$ & $\longrightarrow$ & + & + \\
\hline Or. 4 & $\longrightarrow$ & & - & $\longrightarrow$ & & + & + & + & & + \\
\hline Or. 5 & $\longrightarrow$ & & - & $\longrightarrow$ & & 1 & + & + & & + \\
\hline Or. 6 & + & & $\longrightarrow$ & + & & t+1t & $H$ & HH & $\longrightarrow$ & H \\
\hline Or. 7 & H & & + & H- & & +1 & $\mathrm{HH}$ & $\mathrm{HH}$ & $\longrightarrow$ & $H$ \\
\hline Or. 8 & $H$ & & + & + & & + & + & + & + & H \\
\hline Or. 9 & + & & $\longrightarrow$ & $\longrightarrow$ & & + & $\longrightarrow$ & $\longrightarrow$ & $\longrightarrow$ & 1 \\
\hline Or. 10 & $\longrightarrow$ & & $\longrightarrow$ & - & $\longrightarrow$ & + & $\longrightarrow$ & $\longrightarrow$ & $千$ & + \\
\hline Or. 11 & H & & $H$ & 世 & $\overline{ }$ & + & H & H+H & + & $H$ \\
\hline
\end{tabular}


number of distinguishable lines in each positive precipitin reaction. From Table 1 it is apparent that the genital strains formed a group with the Mycoplasma hominis type 1 strains from outside sources; this group may simply be referred to as type 1 . The oral strains formed a separate group with the type 4 strain; this group may now be referred to as type 4. Between types 1 and 4 there were several cross-reactions. Type 2 is represented by strain Campo and one rat strain, but it has cross-reactions with types 1 and 4 . Type 3 is represented by one strain $G$ and showed no relationship to any other.

Cross-reactions between PPLO groups

The reactions between type 1 antigens and types 2 and 4 antisera showed only single lines in most cases, and never more than two lines. The identity of the corresponding antigens was established by coincidence of these lines, where the various antigenic preparations made from the members of the type 1 group were tested simultaneously against type 4 sera. The commonest type 2 or type 4 antigen shared by type 1 was thus defined and designated $a$; the second, less common, was designated $b$. (Table 2).

The phenomenon referred to by Pease \& Laughton (1965), where antigens were more clearly definable by means of the homologous antibody than by the antigen, occurred in the present work also, and was of importance in the application of precipitin or antigen absorption to the further analysis of the antigenic structure of these groups. Type 4 antigens did not react, at normal concentrations, with Gt. 2 (type 1) antiserum, although Gt. 2 antigen reacted with all type 4 antisera, giving either one or two lines; but Gt. 2 antiserum, mixed with homologous antigen or with any other type 1 antigen, had the effect of eliminating these lines, i.e. of absorbing antigens $a$ and $b$. Thus the presence of antigens $a$ and $b$ in type 4 strains, presumably in too small quantities to produce a visible line of precipitation, was indicated. This was verified by increasing the relative concentration of the type 4 antigens, as far as the technique allowed, when a faint reaction was produced.

Absorption of type 1 antigens containing components $a$ and $b$, with any type 1 antiserum (irrespective of whether both $a$ and $b$ showed strongly in cross-reaction of type 4 antiserum with the type 1 antigen homologous with the absorbing antiserum), had the effect of removing antigens $a$ and $b$. Thus it appears that antigens $a$ and $b$ were normally present in type 1 strains although only one or the other might appear as a visible line in a cross-reaction.

Since antigens $a$ and $b$ were common to types 1,2 and 4, it was possible to determine whether any antigens other than these were present in the type 1 homologous system. This was done in two ways. Type 1 antigen (Gt. 6) with demonstrable components $a$ and $b$ was placed in the centre cup and surrounded by cups containing types 2 and 4 (Or. 1) sera, interspaced with type 1 antisera (Gt. 2 and 3 and $\mathrm{H} \mathrm{26}$ ). Two lines, representing $a$ and $b$, showed continuously around the central cup. Opposite the type 1 sera a further strong line appeared, overlapping the $a$ and $b$ lines where they deviated opposite the types 2 and 4 antisera. This further antigen, specific to type 1, was named $c$. It was also demonstrated by absorbing the type 1 (Gt. 6) antigen with type 4 (Or. 1) serum, which had the effect, in the same arrangement of sera and antigens as previously, of removing line $a$ and $b$, and leaving line $c$. In a further test, with the absorbing antigen in the central cup, the type 1 antisera were placed in neighbouring cups. The residual line $c$ was then continuous, showing 
it to be present equally in strains Gt. 2, 3, $\mathrm{H} 26$. The identity of $c$ in the remaining type 1 antigens, for which antisera were not available, was established by the continuity of lines when these antigens were placed in central cups and tested against the available antisera.

Table 2. The antigenic structure of Mycoplasma hominis types

$\begin{array}{ll}\text { Type 1 } & a, b, c, f, g \\ \text { Type 2 (Campo) } & a, b, f, g, h \\ \text { Type 3, 'G' } & j, k \\ \text { Type 4 } & (a), *(b), d, e, f, g\end{array}$

* Letters in parentheses indicate factors normally present in sera but demonstrable only in concentrated antigenic preparations.

By the second of these methods, the existence in type 4 of antigens other than $a$ and $b$ was demonstrated. Each of two type 4 antigens (Or. 6 and Or. 7) was absorbed with each of two type 1 sera (Gt. 3 and Gt. 4). These four absorbed antigens were placed in central cups, each surrounded with cups containing five type 4 sera (Or. 1, Or. 2, Or. 3, Or. 4 and $\mathrm{н}$ 110). Against these sera, the absorbed antigens gave two lines in each case, except with serum Or. 3, where one line only was discernible. The lines were continuous between neighbouring cups, and thus represent two further antigens, $d$ and $e$, of which $d$ only appears in Or. 3.

Two further antigens appearing in most type 4 strains were identified by their reaction against Gt. 3 and $H \mathbf{2 6}$ sera, but against no other type 1 sera. These two antigens were distinguishable from $a, b$ and $c$ because they appeared only in reaction against these two sera, whereas all type 1 sera contained $a, b$ and $c$ antibodies in large amounts. They were distinguishable from $d$ and $e$ because they did not appear in, for example, Or. 4 and $\mathrm{H} 110$, where $d$ and $e$ were strongly represented. They were distinguishable from one another by absorption of Or. 8 with Gt. 3 or $\mathrm{H} 26$ serum, after which the antigen continued to react with the alternative serum. Each of these antigens formed a single line when the positive antigens were placed contiguously around the appropriate serum. These two antigens were named $f$ and $g$. The type strain of type 2, Campo, by the same criteria, possessed antigens $a, b$ and $f$, and also an antigen peculiar to the group, named $h$. The strain $\mathrm{E}$, isolated from a rat, reacted very strongly with Campo serum, and possessed $a, f$ and $g$ in addition to $h$.

Type 3 was represented only by strain $\mathrm{G}$, which showed two distinguishable lines with the homologous serum. These antigens are called $j$ and $k$ in Table 2.

\section{Cross-reactions between PPLO and bacteria}

Table 3 shows the cross-reactions between the bacterial and PPLO strains, using the sera listed above, those against the derived strains Bact. Or. 4 and Bact. Or. 9, and the corynebacterial variant of SM, and also those listed by Pease \& Laughton (1965). The antigenic component 12, common to several bacterial strains (Table 4), was detected at this stage by the reaction of the sera Bact. Or. 4 and Bact. Or. 9 with both the Edmunds GP 2 strain of Haemophilus vaginalis and the $H$. influenzae group. The line of precipitation proved to be continuous between contiguous, alternative cups containing the several types of antigen or antiserum. Relationships between bacterial strains isolated as such, and those derived from PPLO, were shown by 
reactions of SM serum and antigen with D 5 antigen. By cross-absorption, two common antigens, 41 and 42, were identified. A third antigen was common to $\mathrm{D} 5$, Bact. Or. 4 and 9 T.

Table 3. Cross-reactions between bacteria and PPLO

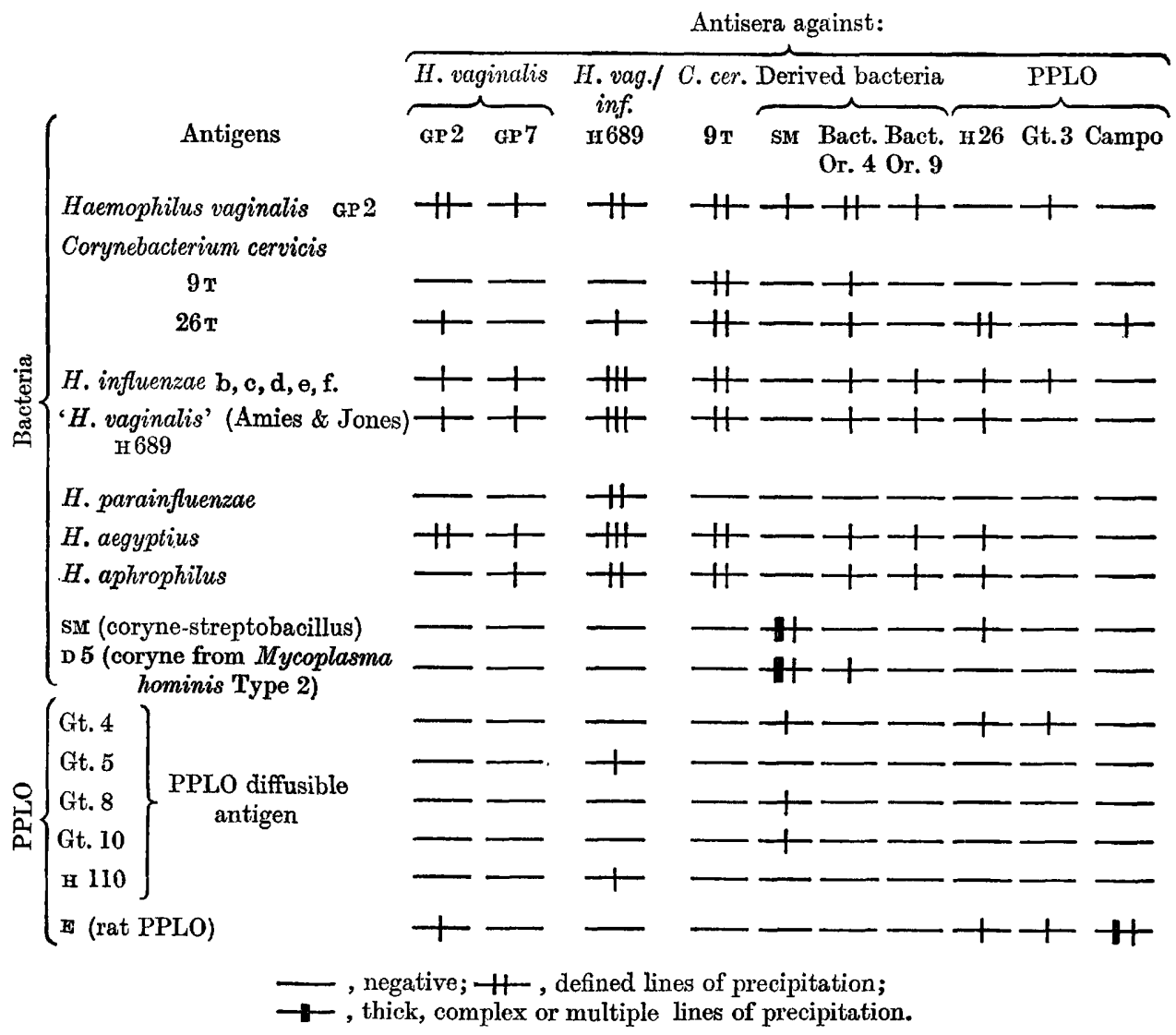

The cross-relationships between PPLO and bacteria were examined further. The serum $\mathrm{H} 26$ (Mycoplasma hominis type 1) reacted positively with most members of the Haemophilus influenzae group, as antigenically defined by Pease \& Laughton (1965), an example being $\mathrm{H} 689$ (H. vaginalis, Amies \& Jones). When $\mathrm{H} 689$ was placed opposite the sera н 26, Bact. Or. 4 and Bact. Or. 9, the line representing this precipitin reaction was continuous for all three. Thus the common antigen was present in these bacterial strains derived from PPLO. The identity of the antigen in reactions between $\mathrm{H} 26$ (PPLO) serum and the remaining members of the $H$. influenzae group was established in the same way. This antigen, common to type 1 mycoplasma and to all listed strains of $H$. influenzae, was absorbed from $H$. influenzae $\mathrm{f}$ (noncapsulated) antigens by the following antibacterial sera: GP 2, GP 7 and $9 \mathrm{~T}$, but not by $\mathrm{H} 689$. The antigen established in the scheme of Pease \& Laughton (1965) which fulfils these requirements is $\mathbf{1 7}$, and it is thus concluded that 17 is an antigen common to mycoplasma, Haemophilus, Corynebacterium and also to the bacteria of corynebacterial morphology derived from mycoplasma. 
The second common antigen was detectable by the reaction between Gt. 3 (mycoplasma type 1) antiserum and GP2 (Haemophilus vaginalis, Edmunds). This was distinct from the first common antigen (17) because there was no reaction between H 26 or Bact. Or. 4 sera and GP 2 antigen. By identity of lines, where GP 2 antigen was

Table 4. Distribution of antigens in PPLO and bacteria

\begin{tabular}{|c|c|c|}
\hline Specific types & Specific antigens & Group antigens \\
\hline $\begin{array}{l}\text { Haemophilus vaginalis } \\
H . \text { influenzae, H. parainfluenzae, } \\
\text { 'H. vaginalis' (A. \& J.) }\end{array}$ & $\begin{array}{l}1,2,3,4,5,6,7,8,9,10 \\
31,32,33,34,35,36,37,38\end{array}$ & $\begin{array}{l}11,12,17,39 \\
11,12,17,18,39,\end{array}$ \\
\hline Corynebacterium cervicis & $15,16,19,20,21$ & $11,17,18,25,40, g$ \\
\hline $\begin{array}{l}\text { Corynebacteria associated with } \\
\text { Campo and with Streptobacillus } \\
\text { moniliformis }\end{array}$ & 41,42 & $25, g, \beta$ \\
\hline $\begin{array}{l}\text { Corynebacteria associated with oral } \\
\text { PPLO }\end{array}$ & $43,44,45$ & $12,17,25,39,40$ \\
\hline $\begin{array}{l}\text { Mycoplasma hominis type } 1 \\
M . \text { hominis type } 2 \\
\text { M. hominis type } 4\end{array}$ & $\begin{array}{l}a, b, c, f \\
a, b, f, h \\
a, b, d, e\end{array}$ & $\begin{array}{l}17,39,40, g, \alpha, \beta \\
40, g \\
g, \alpha\end{array}$ \\
\hline
\end{tabular}

surrounded by contiguous cups containing Gt. 3 serum, alternating with GP 2 and Bact. Or. 9 sera, it was determined that the same antigen occurred in Bact. Or. 9. This antigen did not appear to have been previously determined and was named 39. A trace of antigen 39 appeared to exist in the rat strain $\mathbf{E}$, and in $H$. influenzae.

The third and fourth common antigens were detectable by the reaction between н 26 (mycoplasma type 1) serum and $26 \mathrm{~T}$ (Corynebacterium cervicis; Laughton, 1954) antigen. Two lines were visible. These were distinguishable from antigen 17 because with н 26 serum against $26 \mathrm{~T}$ and Haemophilus influenzae $b$ and $c$ antigens, in contiguous cups, these lines of precipitation crossed, and thus showed non-identity with, the line between $\mathbf{2 6}$ and the $\boldsymbol{H}$. influenzae strains. They were also distinct from 39 because $26 \mathrm{~T}$ antigen did not react with Gt. 3 antiserum. One of these two lines was found, by the test of $26 \mathrm{~T}$ antigen against antisera including н 26 , in contiguous cups, to be present in the Campo (Mycoplasma hominis type 2) and Bact. Or. 9 sera. The other showed lines of identity, in the same way, with type 1 and type 4 PPLO sera against $26 \mathrm{~T}$ antigen, and by absorption was identified in $\mathrm{H} 110$, Or. 1, 2, 3, 4, 6, 8,9 and 11 ; Gt. $2,4,6,7,10,11,15$ and 16 , and the streptobacillus SM (a trace). This antigen appears to be $g$; the second line in the $26 \mathrm{~T}, \mathrm{H} 26$ reaction was not identifiable with any previously named antigen and was called 40 .

\section{Diffusible antigens}

Two diffusible antigens, of the type described by Freimer, Krause \& McCarty (1959) and Pease (1963) were also identified, to a limited extent. The antigens extracted from $\mathrm{H} 110$ and Gt. 5 medium reacted positively with 689 (Haemophilus influenzae, 'vaginalis', Amies and Jones) serum; the same antigen was detected in H. influenzae b (non-capsulated), by identity of lines. Extracts Gt. 4, Gt. 8 and Gt. 10 reacted with SM serum. These diffusible antigens were named $\alpha$ and $\beta$, respectively. 


\section{DISCUSSION}

The evidence in Tables 1 and 2 confirms the conclusions of Huijsmans-Evers \& Ruys (1956), Edward \& Freundt (1956) and subsequent authors, that Mycoplasma hominis type 1 consists of human genital strains, and type 4 of human oral strains. Type 2, represented by Campo, also of genital origin, has close relationships with strains from the respiratory passages of rats. This is true not only of strain $\mathrm{E}$, but also of other rat isolates (Lemcke, 1964; Morton, H. E., personal communication). Types 1, 2 and 4 are antigenically closely related, as is already known, and the shared antigens have been defined in this paper. Type 3, of which very few strains have been recorded, is apparently unrelated.

The distribution of shared antigens shown in Table 4 provides evidence that the corynebacterial variants which have been claimed to be derived from PPLO (Minck, 1953; Wittler, Cary \& Lindberg, 1956; Smith, Peoples \& Morton, 1957; Pease \& Laughton, 1962; Pease, 1962;H.E. Morton, personal communication) and the unrecorded examples quoted in this paper are, in fact, what they appear to be, since those examined in this study had several antigens in common, both with PPLO and other corynebacteria, and with members of the Haemophilus groups. And it is notable that the strains of bacteria most recently derived from PPLO (the oral derivatives in Table 4) possess the largest number of shared antigens. This provides support for the view that the PPLO are the L-forms of these and similar bacteria and, if this is true, then the name Mycoplasma hominis is invalid. Apart from the question of bacterial origin, $M$. hominis type 1 shares antigens with Haemophilus influenzae, including the diffusible antigen $\alpha$, which may be regarded as of cell-wall origin (Freimer et al. 1959; Pease, 1963), but none with $M$. hominis type 3 that was detectable by the methods employed.

Haemophilus may conceivably be a Gram-negative (or weakly Gram-positive) derivative of Corynebacterium, as Streptobacillus moniliformis has already proved to be (Pease, 1962). The relationship of Corynebacterium, Haemophilus and PPLO, as a degenerative series, was suggested by Pease \& Bisset (1962). The apparent relationship between PPLO and Haemophilus influenzae is borne out by the similarity of their DNA base ratios (Sueoka, 1961). This bacterium not only has a hitherto unexplained relationship with myxoviruses, but also produces L-forms which resemble morphologically the filamentous stages of these large viruses (Pease $\&^{2}$ Bisset, 1962). Its close connexion with PPLO parasitic upon mammalian mucous membranes is of theoretical interest.

The evidence that PPLO are L-forms of corynebacteria and related genera now includes repeated experimental transformations of one into the other, similarity of base ratios, and the sharing of several identifiable antigens.

No claim for the completeness of this list of antigens can be made, nor is it known to what extent the differences between the types, as now defined, may be due to reversible phase changes.

Some of these antigens showed signs of lability, and it is possible that the tendency to imbalance between homologous antigens and antisera (cf. Pease \& Laughton, 1965) was due to their acting as haptens, so that their degree of reactivity may have depended upon the molecular associations in which they occurred at different times. A similar imbalance between antibodies and homologous antigens was observed by 
Brown \& Nunemaker (1942) in reactions between Streptobacillus moniliformis and rat PPLO. A further point arises from these authors' work. Pease (1962) showed an antigenic relationship between $S$. moniliformis and human mycoplasmas. In the present work and in that of Lemcke (1964) the PPLO of rat origin proved to be type 2, and in the present work a bacterium (SM) associated with a strain of $S$. moniliformis fell into the same group, whereas the human oral and genital strains isolated in this laboratory were types 4 and 1, respectively. Although the classical type 2 (Campo) is a human genital strain, it is not comparable to the type 1 strains in frequency from this source, and thus it appears that the streptobacillus-mycoplasma type 2 group normally occurs in animals. The origins of type 3 are still obscure, since it is apparently unrelated to the remainder.

\section{REFERENCES}

Brown, T. McP. \& Nunemaker, J. C. (1942). Rat-bite fever. A review of American cases with re-evaluation of etiology: report of cases. Bull. Johns Hopkins Hosp. 70, 201.

CARD, D. H. (1959). PPLO of human genital origin; serological classification of strains and antibody distribution in man. Br. J. vener. Dis. 35, 27.

Coriell, Ll., Fabrizio, D. P. \& Wilson, S. R. (1959). Comparison of PPLO strains from tissue culture by complement fixation. Ann. N.Y. Acad. Sci. 79, 574.

Edward, D. G. FF. \& Fitzgerald, W. A. (1954). Inhibition of growth of pleuropneumonia-like organisms by antibody. J. Path. Bact. 68, 23.

Edward, D. G. FF. \& Freundt, E. A. (1956). The classification and nomenclature of organisms of the pleuropneumonia group. J. gen. Microbiol. 14, 197.

Freimer, E. H., Krause, R. M. \& McCarty, M. (1959). Studies of L-forms and protoplasts of group A streptococci. I. Isolation, growth and bacteriologic characteristics. J. exp. Med. 110, 853.

Huijsmans-Evers, A. G. M. \& RuYs, A. C. (1956). Microorganisms of the pleuropneumonia group (family of Mycoplasmataceae) in man. II. Serological identification and discussion of pathogenicity. Antonie van Leeurenhoek, 22, 377.

Laughton, N. (1954). A study of a bacterium isolated from the human cervix. J. Path. Bact. 67, 169.

LemCKE, R. M. (1964). A comparison of various species of Mycoplasma by gel diffusion. J. gen. Microbiol. 35, ii.

Minck, R. (1953). Récherches sur l'origine des organismes du type de la péripneumonie trouvées dans les organes génitaux de la femme. C. r. hebd. Séanc. Acad. Sci., Paris, 236, 250.

Nicol, C. S. \& EDward, D. G. FF. (1953). Role of organisms of the pleuropneumonia group in human genital infections. Br. J. vener. Dis. $29,141$.

Norman, M. C., Saslaw, S. \& KunN, L. R. (1950). Antigenic similarity of five human strains of pleuropneumonia-like organisms. Proc. Soc. exp. Biol. Med. 75, 718.

Pease, P. E. (1962). Evidence that Streptobacillus moniliformis is an intermediate stage between a corynebacterium and its L-form or derived PPLO. J. gen. Microbiol. 29, 91.

PEASE, P. E. (1963). Bacterial origin of certain viruses: identity of the Eaton agent with Streptococcus MG. Nature, Lond. 197, 1132.

Pease, P. E. \& Bisset, K. A. (1962). The effect of parasitism on Gram-positive bacteria with reference to the origin of certain types of virus. Nature, Lond. 196, 357.

Pease, P. E. \& Laughton, N. (1962). Observations on corynebacteria and related pleuropneumonia-like organisms (PPLO). J. gen. Microbiol. 27, 383.

Pease, P. E. \& Laughton, N. (1965). The antigenic structure of Haemophilus and Corynebacterium species from the human genital tract claimed to be associated with or derived from Mycoplasma hominis. J. gen. Microbiol. 41, 293.

Smith, P. F., Peoples, D. M. \& Morton, H. E. (1957). Conversion of pleuropneumonialike organisms to bacteria. Proc. Soc. exp. Biol. Med. 96, 550. 
SuEora, N. (1961). Variation and heterogeneity of base composition of deoxyribonucleic acids : a compilation of old and new data. J. mol. Biol. 3, 31.

Taylor-Robinson, D., Somerson, N. L., Turner, H. C. \& Chanock, R. M. (1963). Serological relationships among human mycoplasmas as shown by complement fixation and gel diffusion. J. Bact. 85, 1261.

Tourtelotte, M. E. \& JAcobs, R. E. (1959). Physiological and serological comparisons of PPLO from various sources. Ann. N.Y. Acad. Sci. 79, 521.

Viluemot, J. M. \& Provost, A. (1959). Récherches immunologiques sur la péripneumonie. VI. Bases d'une classification sérologique des microorganismes du genre Mycoplasma. Revue Élev. Méd. vér. Pays trop. 12, 369.

Wittler, R. G., CARY, S. G. \& Lindberg, R. B. (1956). Reversion of a pleuropneumonialike organism to a corynebacterium during tissue culture passage. J. gen. Microbiol. 14, 763. 